\title{
Strain Life of Shot Peening AA 2024-T4
}

\author{
Adnan N. Abood ${ }^{1}$, Ali H. Saleh ${ }^{2}$, Raid K. Salem ${ }^{1}$, Ghaith A. Kadhim ${ }^{1} \&$ Zainab W. Abdullah ${ }^{1}$ \\ ${ }^{1}$ Technical College/Baghdad, Baghdad, Iraq \\ ${ }^{2}$ Institute of Technology, Baghdad, Iraq \\ Correspondence: Zainab W. Abdullah, Technical College/Baghdad, Baghdad, Iraq. Tel: 964-770-296-9532. \\ E-mail: zainab.wa83@yahoo.com
}

Received: September 22, 2012 Accepted: October 9, 2012 Online Published: December 10, 2012

doi:10.5539/jmsr.v2n1p113 URL: http://dx.doi.org/10.5539/jmsr.v2n1p113

\begin{abstract}
This research involved studying the effect of shot peening, by steel balls, on Low Cycle Fatigue (LCF) of aluminum alloy AA 2024-T4 at different peening times $(5,10,15,20 \& 30 \mathrm{~min})$. Shot peening helped to increase the tensile and yield strength $\left(\sigma_{\mathrm{u}}, \sigma_{\mathrm{y}}\right)$ to reach the highest values at the time of 15 minutes and then declined. Strain hardening coefficient (n) increased to some extent, which recorded an indication of the possibility of continued cyclic hardening behavior of the alloy during LCF after the peening. LCF tests showed that un-peened AA 2024-T4 was more resistant especially at rates lower than 9x10 $10^{3}$ cycles, then for 15 minutes. shooting, a pronounced improvement in LCF life down to the number of cycle's equal to $10^{5}$ cycles. SEM showed that the size of dimples, length of secondary cracks and the voids increased for peened specimens were especially at high cyclic strains near the strains of $\sigma_{\mathrm{u}}$.
\end{abstract}

Keywords: low cycle fatigue, shot peening, Al-alloy, residual stress

\section{Introduction}

Surface treatment of engineering components by shot peening is a very effective and widely used technique for improving their resistance to fatigue failure. This is particularly the case in the aeronautics industry where structural components that are sensitive to fatigue are routinely shot peened (Everett, Prabhakaran, Newman, \& Dubberly, 1993; Montross, Wei, Ye, Clark, \& Mai, 2002; Anand \& Parks, 2004; Farahani, Kodric, \& Ghahramani, 2005; Bhuvaraghan, Srinivasen, \& Maffeo, 2010). Shot peening should have an impact on the arrest of fatigue cracks. Firstly, work hardening of the peened layer should increase the resistance to the development of the crack tip plasticity. Secondly, the compressive residual stress should bring about closure of the crack and, therefore, the resistance to crack opening should increase (Guagliano \& vergani, 2002; Cartis, De Los Rios, Rodopoulos, \& Levers, 2003; Afazov, Becker, \& Hyde, 2010; Soady \& Mellor, 2011). Borrego, Abreu, Costa and Ferreira (2003) had studied low-cycle fatigue tests in AA 6082-T6 and AA 6060-T6 alloys. Cyclic softening and hardening for axial strain amplitudes respectively lower and higher than $0.82 \%$, were observed for alloy AA 6082-T6, whereas alloy AA 6060-T6 presented stable cyclic behavior. Alloy 6060-T6 exhibits nearly ideal massing behavior and alloy AA 6082-T6 non-massing behavior and the type of deformation behavior in AlMgSi alloys seems to be influenced by the dispersoid. Benedetti, Bortolamedi, Fontanari and Frendo (2003) had studied the fatigue behavior of the AA 6082- T5 alloy subjected to two different shot peening treatments. During the first part of cyclic loading both materials undergo to stress relaxation, which shows a strong dependence on the external applied load and on the initial surface microstructure, both material conditions reach early a stabilized value of surface residual stress, depending on the loading level. The fatigue behavior of the two peening conditions cannot be completely explained considering the effect of residual stresses. Asquith, Yerokhin, Yates and Matthews (2006) had studied the combination of shot-peening pre-treatment with Plasma Electrolytic Oxidation (PEO) coating to improve the fatigue performance of AA 2024-T351 Al-alloy. The effect of a duplex surface treatment is an increased fatigue limit when compared to aluminum treated singularly with PEO. Secondary observations are that the duplex treatment provides microhardness and residual stress profiles which are preferable for mechanical integrity of the coating-substrate system, and that shot-peening alters the failure mechanism of PEO-treated components. Mehmood and Hammouda (2007) had studied the effect of shot peening parameters such as shot size, nozzle pressure, nozzle distance, impingement angle and exposure time on high strength aluminum alloy AA 2024 mostly used in air craft industries for cyclic loading applications. The results showed that shot peening can be applied to increase the fatigue life of the aluminum alloy under optimum 
conditions otherwise may not be reached appropriate results and even it may cause adverse effects. Also the beneficial effect of the process is greater at long fatigue lives than at short fatigue lives. Aghaie-Khafri and Zargaran (2010) had studied the cyclic stress-strain response and the low-cycle fatigue life behavior of an aluminum alloy AA2618-T61 forged disc. The forged samples exhibit a continuous cyclic hardening at total strain ranges $0.7 \%$ and $0.9 \%$ and cyclic softening at total strain range of $0.5 \%$. The experimental results obtained reasonably follow the Coffin-Manson equation.

\section{Method}

The material which was used for this work is aluminum alloy AA 2024-T4. The apparatus used was cantilever fatigue testing machine. The chemical composition of the material is given in Tables 1 and 2.

Table 1. Chemical composition of AA 2024-T4

\begin{tabular}{llllllll}
\hline & $\% \mathrm{Zn}$ & $\% \mathrm{Si}$ & $\% \mathrm{Fe}$ & $\% \mathrm{Mn}$ & $\% \mathrm{Mg}$ & $\% \mathrm{Cu}$ & $\% \mathrm{Al}$ \\
\hline $\begin{array}{l}\text { Nominal chemical composition } \\
\text { AA 2024-T4 }\end{array}$ & 0.25 & 0.5 & 0.5 & $0.3-0.9$ & $1.2-1.8$ & $3.8-4.9$ & Bal. \\
AA 2024-T4 & 0.029 & 0.267 & 0.301 & 0.606 & 1.47 & 4.31 & Bal. \\
\hline
\end{tabular}

Table 2. Mechanical properties of AA 2024-T4

\begin{tabular}{|c|c|c|c|c|}
\hline & $\begin{array}{l}\text { Engineering Tensile } \\
\text { Strength (MPa) }\end{array}$ & $\begin{array}{l}\text { Engineering Yield } \\
\text { Strength }(\mathrm{MPa})\end{array}$ & $\sigma_{\mathrm{u}} / \sigma_{\mathrm{y}}$ & Elongation $(\%)$ \\
\hline $\begin{array}{c}\text { Nominal Mechanical } \\
\text { Properties AA 2024-T4 }\end{array}$ & 470 & 325 & - & 20 \\
\hline AA $2024-T 4$ & 487 & 345 & 1.41 & 22.5 \\
\hline
\end{tabular}

Universal testing machine was used for tensile test. The alloy AA 2024 were fabricated into 15 tensile specimens (3 specimens for each condition) and tested in accordance with ASTM B557M-84. Fatigue specimens were manufactured and tested in accordance with ASTM 606-80 (Figure 1). Data has been obtained depending on the mean of the readings using twelve specimens for every condition. Each specimen surface was ground with different grades of emery papers down to ASTM grit 2000. The specimens were also polished with alumina suspension. Peening is done for five exposure time conditions $(5,10,15,20$ and 30 minutes) with average steel shot diameter is $2.7 \mathrm{~mm}$. Roughness test for the six conditions with and without peening was done. The results showed that the surface roughness $(\mathrm{Ra})$ of the un-peened specimens was $0.16-0.19 \mu \mathrm{m}$ which is compatible with the standard value which is $0.2 \mu \mathrm{m}$ maximum according to ASTM 606-80. Shot peening increase surface roughness incrementally to reach $3.8 \mu \mathrm{m}$ at 30 minutes. with $19 \%$ increment comparing with un-peening condition.

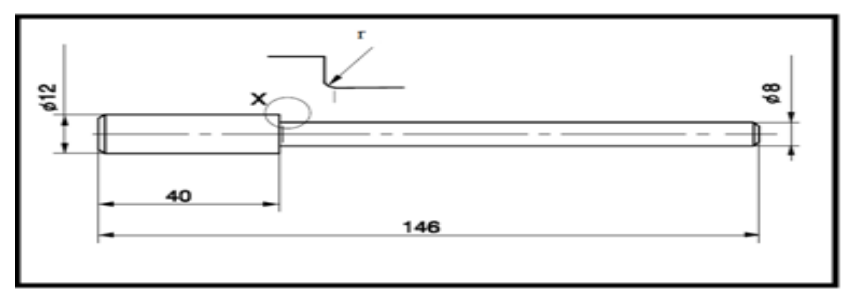

Figure 1. Fatigue specimen (all dimensions in $\mathrm{mm}$ )

\section{Results and Discussion}

With peening, tensile strength $\left(\sigma_{u}\right)$ and yield strength $\left(\sigma_{y}\right)$ slightly increased till 15 minutes then decreased. The tensile strength increased to $505 \mathrm{MPa}$ with about $3.6 \%$ comparing to the as received specimen. The yield 
strength increased to $355 \mathrm{MPa}$ with about $2.8 \%$ increment. The ductility was more affected than the tensile, while yield strength decreased to $13.7 \%$ at 15 minutes, then increases to values less than of un-peening state (Figure 2).

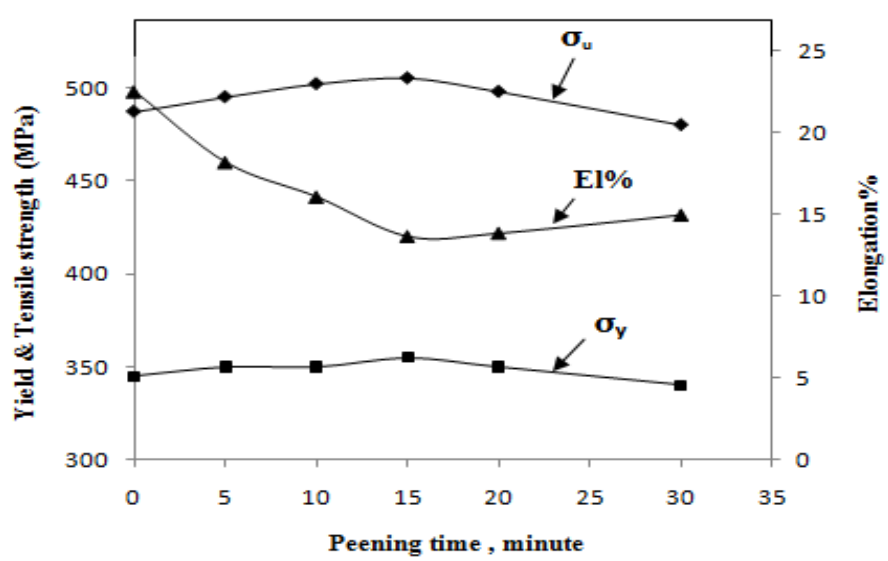

Figure 2. Effect of shot peening on mechanical properties of AA 2024-T4

The tensile strength to the yield strength ratio is in the range 1.41-1.43. This indicates that the aluminum alloy will remain with the same behavior (Rahman, Kadirgama, Noor, Rejab, \& Kesulai, 2009). After 15 minutes peening time the surface roughness became of greater effect than the residual compressive stresses (Figure 3). Surface roughening is generally considered detrimental in terms of fatigue life (due to the presence of micro stress concentrators and accelerated crack initiation). This localized plastic deformation also results in strain hardening which increases the yield strength of the material near the surface. It has been reported that the beneficial effect of strain hardening increases the initiation life since high dislocation densities in the cold worked region results under higher yield stresses. The presence of compressive residual stresses can increase both initiation and crack propagation lives as a result of a reduction in the effective applied tensile stress (Soady, Mellor, Shackleton, Morris, \& Reed, 2011). With increasing peening time, strain hardening exponent ( $n$ ) maintained values higher than 0.24 with a slight change, less than $8 \%$ at 15 minutes, to reach 0.26 . This indicates that the alloy will be cyclically hardened under low cycle fatigue. Typically, metals with a high monotonic strain-hardening exponent $(\mathrm{n}>0.2)$ will harden whereas those with a low monotonic strain hardening exponent $(n<0.1)$ will cyclically soften A rule of thumb, as the material will harden if $\sigma_{\mathrm{u}} / \sigma_{\mathrm{y}}>1.4$ and the material will soften if $\sigma_{\mathrm{u}} / \sigma_{\mathrm{y}}<1.2$. For ratios of $\sigma_{\mathrm{u}} / \sigma_{\mathrm{y}}$ between 1.2 and 1.4 , the material can exhibit hardening, softening, or both. These figures indicate that use of monotonic material properties for fatigue life predictions can sometimes lead to inaccurate results.

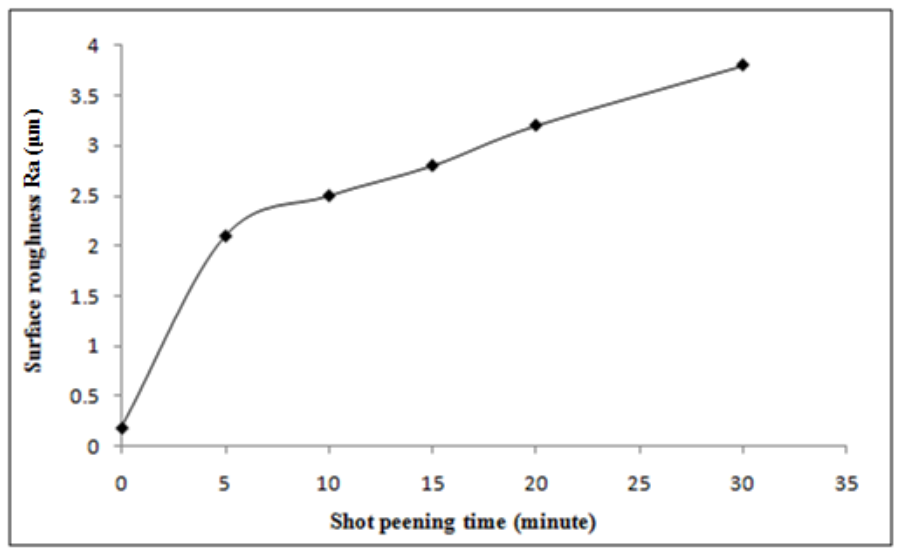

Figure 3. Effect of shot peening on surface roughness 
The Low cycle fatigue curve of un-peened AA 2024-T4 (Figure 4) shows that the value of the fatigue strength exponent(b) equal to -0.12 and the value of the fatigue ductility exponent (c) equal to -0.64 is in the range of all metals in general, which is -0.06 to -0.14 for $b$ and -0.4 to -0.7 for $\mathrm{c}$.

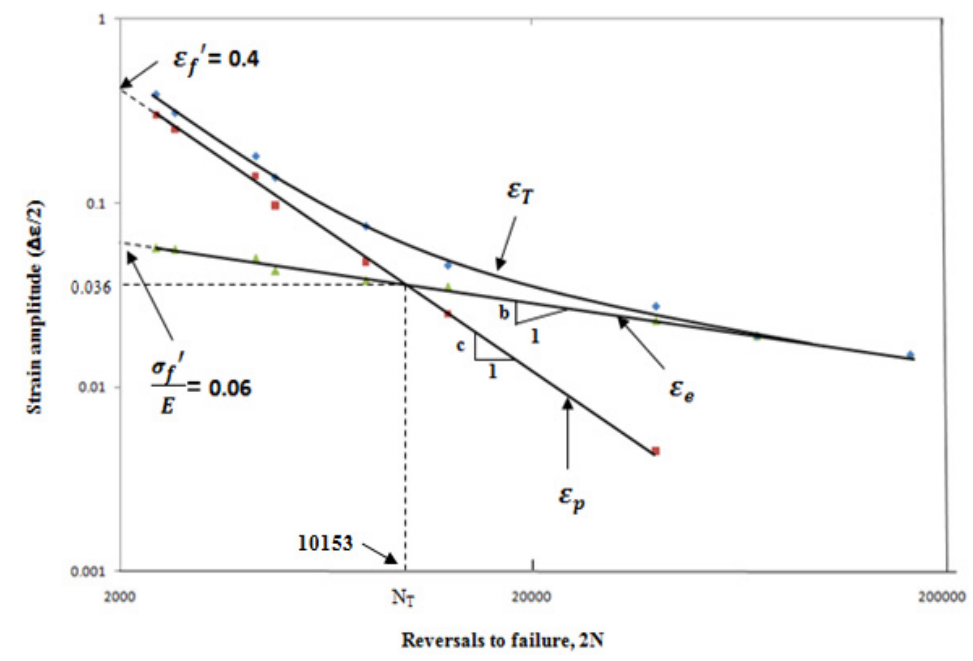

Figure 4. Low cycle fatigue of AA 2024-T4, without shot peening

The transition fatigue life $\left(\mathrm{N}_{\mathrm{T}}\right)$ at which the elastic and plastic component are equal and intersect equal to 10153 cycles. It can be observed from Table (3) that the cyclic strain hardening exponent is close to the monotonic strain hardening exponent.

Table 3. Low cycle fatigue properties of AA 2024-T4 for different shot peening time

\begin{tabular}{llllllll}
\hline \multirow{2}{*}{ Condition } & \multicolumn{2}{c}{$\Delta \varepsilon_{p} / 2=\varepsilon_{f}^{\prime}\left(2 N_{f}\right)^{c}$} & \multicolumn{2}{c}{$\Delta \sigma / 2=\sigma_{f}^{\prime}\left(2 N_{f}^{\prime}\right)^{b}$} & \multirow{2}{*}{$k^{\prime}(\mathrm{MPa})$} & \multirow{2}{*}{$n^{\prime}$} & \multirow{2}{*}{$\mathrm{N}_{\mathrm{T}}$} \\
\cline { 2 - 6 } & $\varepsilon_{f}^{\prime}$ & $\mathrm{c}$ & $\sigma_{f}{ }^{\prime} / E$ & $\mathrm{~b}$ & & & \\
\hline Without peening & 0.4 & -0.64 & 0.06 & -0.12 & 4245 & 0.18 & 10153 \\
Peening 5 minutes & 0.17 & -0.554 & 0.058 & -0.087 & 4824 & 0.157 & 9224 \\
Peening 10 minutes & 0.15 & -0.509 & 0.057 & -0.078 & 4959 & 0.153 & 8142 \\
Peening 15 minutes & 0.11 & -0.4 & 0.055 & -0.06 & 5263 & 0.15 & 7255 \\
Peening 20 minutes & 0.13 & -0.445 & 0.056 & -0.069 & 5112 & 0.155 & 7933 \\
Peening 30 minutes & 0.35 & -0.7 & 0.055 & -0.15 & 4079 & 0.21 & 9674 \\
\hline
\end{tabular}

Low cycle fatigue for 5 minutes shot peening (Figure 5) shows that the value of $\mathrm{c}$ and $\varepsilon_{f}{ }^{\prime}$ is lower than the un-peened whereas $\sigma_{f}{ }^{\prime}$ increased while (b) decreased. In addition to the residual compressive stresses, the plastic straining increase the dislocation density rapidly, which causes a cycled pendent strengthening, termed cyclic hardening (Anand et al., 2004). Comparing with un-peened condition the transition fatigue life $\left(\mathrm{N}_{\mathrm{T}}\right)$ decreased to 9224 cycles (Table 3), while the cyclic strain slightly increased. The values of $n$ and $n^{\prime}$ are equal to 0.249 and 0.157 respectively. The difference between $n$ and $n^{\prime}$ and the increase of $k^{\prime}$ is due to cycling hardening. 


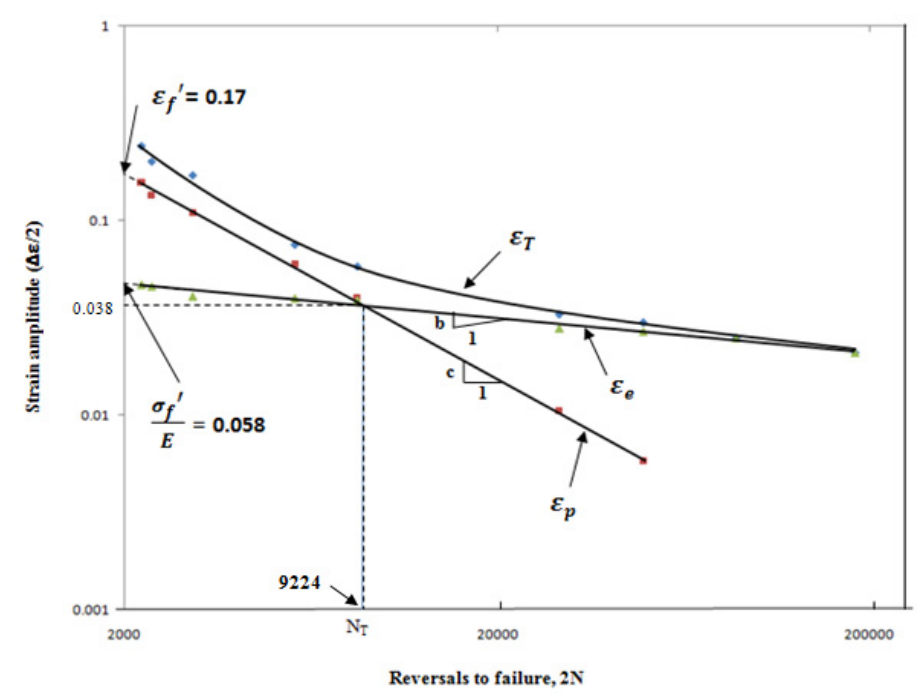

Figure 5. Low cycle fatigue curve of AA 2024-T4, 5 minutes shot peening

Comparing to the as received specimens the values of $\mathrm{c}$ and $\mathrm{b}$ for 10 minutes shot peening (Figure 6) decreased, so, the shot peening decreases the absolute value of $b$ \& $c$ due to the rise in hardness (Yu et al., 1986). The value of $\sigma_{f}{ }^{\prime}$ increased this give a signal for increasing strength. The decreasing of transition fatigue life $\left(\mathrm{N}_{\mathrm{T}}\right)$ indicates the lowering of the number of cycles before transferring from elastic deformation zone to the plastic deformation zone, but with higher cyclic strain. The values of $n^{\prime} \& n$ are 0.15 and 0.26 respectively.

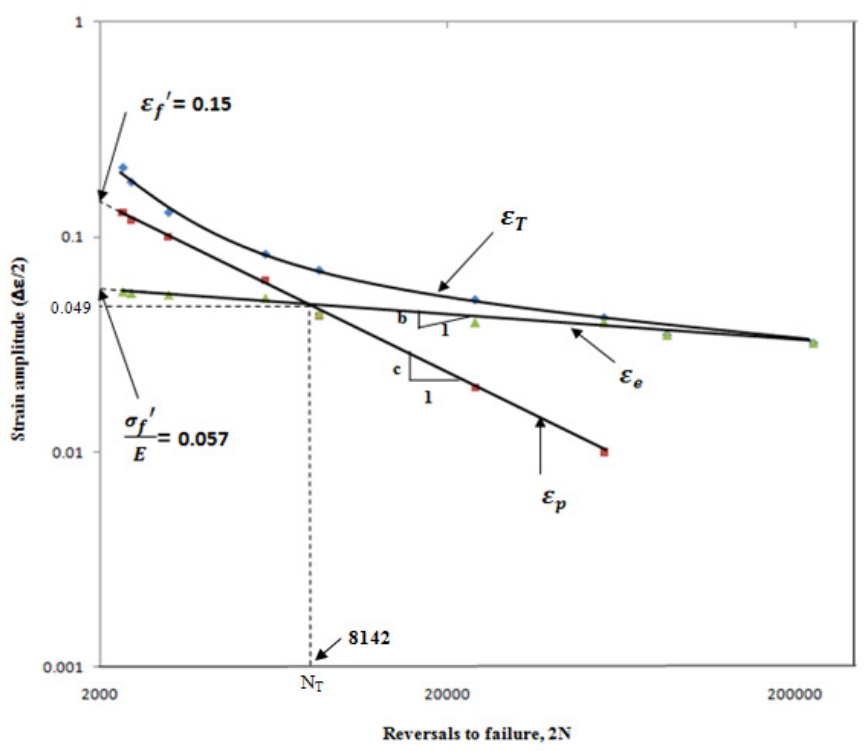

Figure 6. Low cycle fatigue of AA 2024-T4, 10 minutes shot peening

From Table 3, it can be noticed that $\varepsilon_{f}{ }^{\prime}$ value decreased with the increasing of shot peening time to record minimum value at 15 minutes, this indicates that the strain is less at 15 minutes (Figure 7), the increase in strength are invariably accompanied by decreases in ductility, or monotonic true strain at fracture. These associated reductions in the material's ability to undergo plastic deformation without fracture under monotonic loading also manifest themselves in a corresponding decrease in its fatigue ductility coefficient, $\varepsilon_{f}{ }^{\prime}$. Reduced values of the latter material property mean that lower fatigue lives will result from application of any given value of plastic strain range, $\varepsilon_{p}$. It also has the highest value of $\sigma_{f}{ }^{\prime}$ and the lowest value of $b$. The fatigue strength coefficient, $\sigma_{f}{ }^{\prime}$ correlates positively with measures of a material's resistance to monotonic plastic deformation such as tensile yield strength, $\sigma_{\mathrm{y}}$, or hardness. Consequently, standard approaches to improve high cycle fatigue 
performance have involved material compositions and processing means to increase strength, including use of alloying elements, heat treating, and special surface hardening treatments (e.g., shot peening, carburizing, nitriding, etc.), (Anand et al., 2004). The fatigue transition life $\left(\mathrm{N}_{\mathrm{T}}\right)$ is the lowest, therefore for higher lives the fatigue resistance of the alloy will be determined by its strength (Borrego et al., 2003. It can be observed that $\mathrm{N}_{\mathrm{T}}$ records minimum value to meet a cyclic strain equal to 0.05 comparing with the unpeeing state.

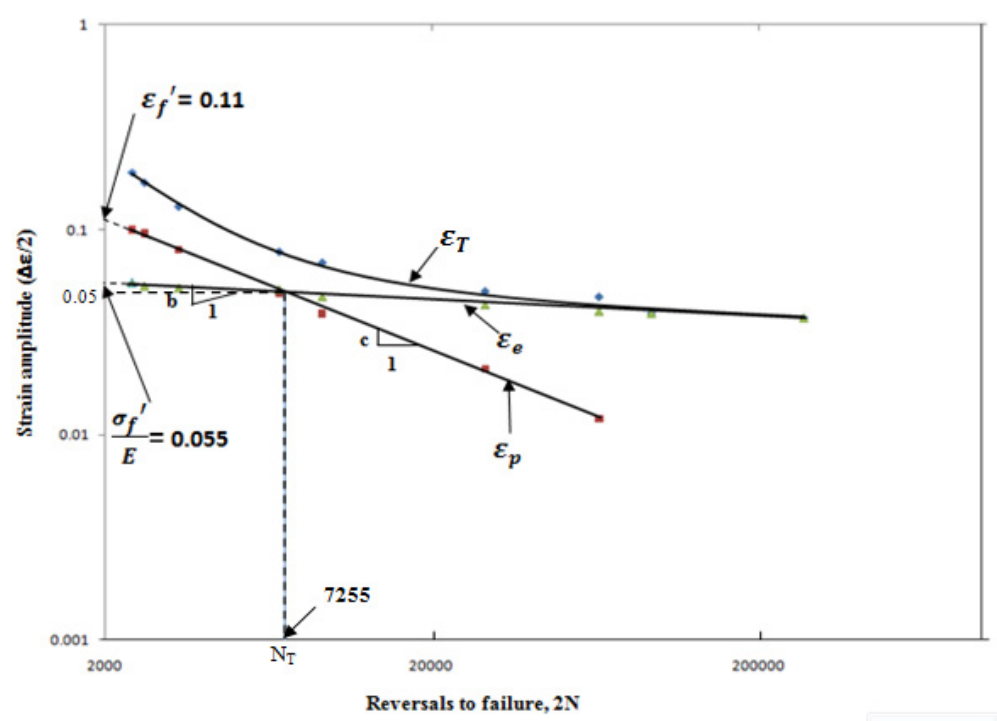

Figure 7. Low cycle fatigue of AA 2024-T4, 15 minutes shot peening

For 20 and 30 minutes shot peening (Figures 8 and 9), the values of $\varepsilon_{f}^{\prime} \& \mathrm{c}$ increased to values less than the un-peened alloy, except for 30 minutes, where it has a value of c higher than the un-peening state. When the value of $b$ increases to reach a value higher than 30 minutes, the value of $\sigma_{f}{ }^{\prime}$ decreases to its lowest value. Fatigue behavior of shot peened specimens cannot be fully explained by the residual stress effect. Another important factor is the increased surface roughness during the shot peening process, which reduces the beneficial effect of the compressive residual stress. Surface roughness acts like initial defects on the specimen's surface and reduces the fatigue strength in the similar way of surface notch (Xiang et al., 2010). The fatigue transition life $\left(\mathrm{N}_{\mathrm{T}}\right)$ increased to a value close to the case without peening, which pointed an increase in the number of cycles before reaching the plastic deformation region.

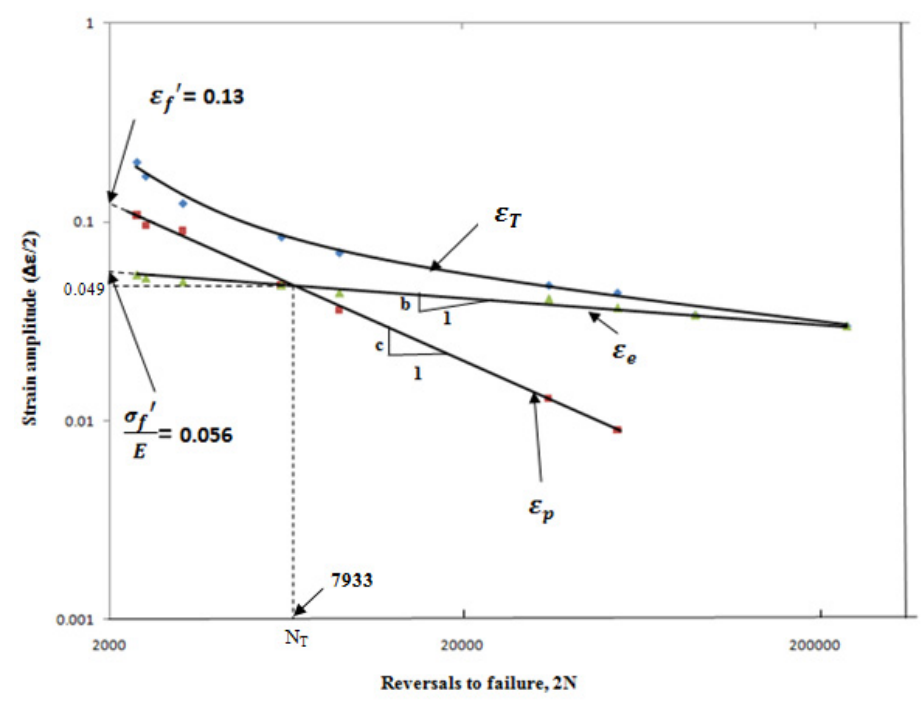

Figure 8. Low cycle fatigue of AA 2024-T4, 20 minutes shot peening 


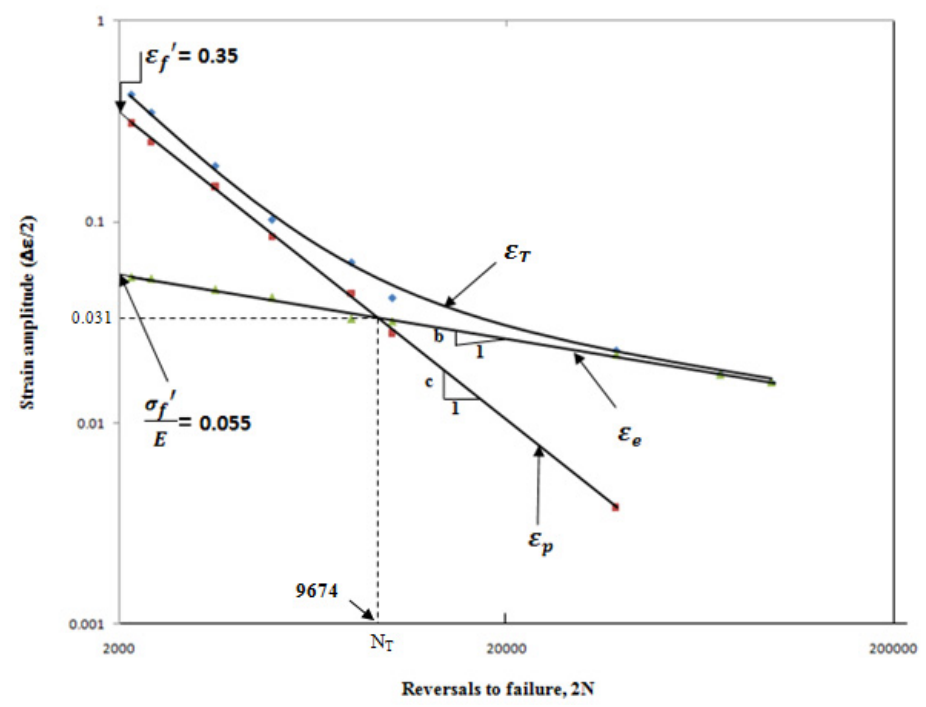

Figure 9. Low cycle fatigue of AA 2024-T4, 30 minutes shot peening

It can be noticed from the plastic deformation (Figure 10), that there is a variation in the AA 2024-T4 behavior when it shot peened with the pre-mentioned conditions. This variation in the behavior of the alloy is restricted in plastic deformation range between $0.039-0.047$ and meets a number of cycles equal to approximately 9000 cycle to record the highest cycling hardening at the un-peening state followed by the peening states.

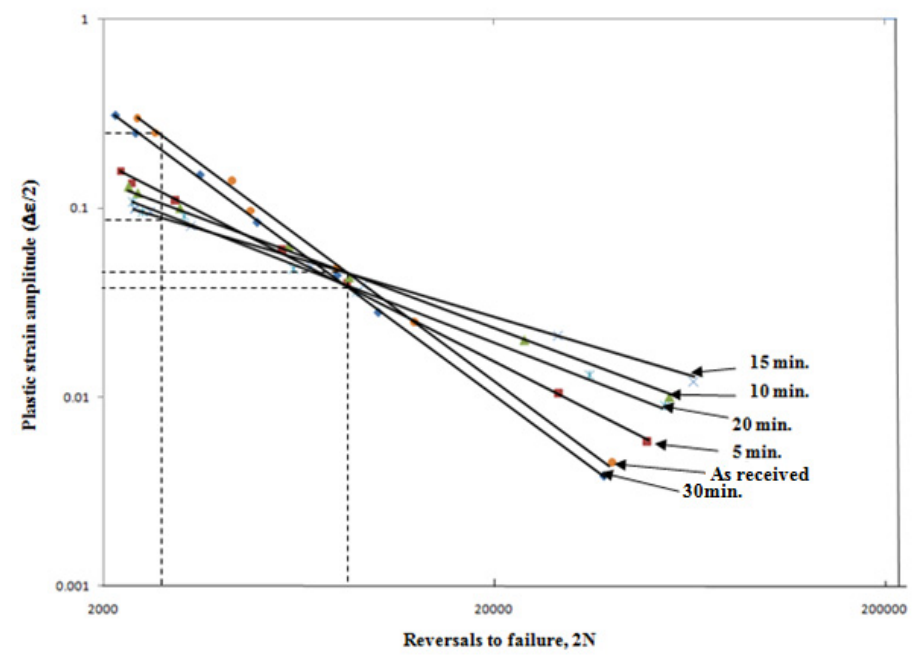

Figure 10. Plastic strain curve

This behavior is varied after approximately 9000 cycle to record the highest cycling hardening at 15 minutes. This behavior conform studies that the effect of shot peening on AA2024-T4 is a limited effect in the first 9000 cycles then the effect begins to increase in the direction for more than 105 cycles. Clearly, the benefits from peening are linked to the applied stress; at high stresses there is only a slight improvement (if any) whereas at low stresses there can be a significant improvement in fatigue life. This accords with normal fatigue observations in that, at low stresses, fatigue life is particularly sensitive to surface condition, and in peening, the crack retardation process caused by the surface residual stresses can play a major role. At higher stresses, however, many cracks initiate rapidly, and life is controlled by crack growth. At low fatigue stresses, the growth of small surface flaws is a dominant factor in fatigue life, so large life extension can be achieved by appropriate peening methods, which will reduce the propagation of these small flaws. However, at higher stresses poor peening can be detrimental to fatigue life (Shorp et al., 2001). Relaxation is another reason for this behavior, when strain 
amplitude is large, the residual stress relaxes rapidly and the relaxation slows down with the decrease of strain amplitude (Yonghe et al., 1986). It can be noticed from Figure 10 that there is a pronounced decrease in the plastic deformation value with increasing shot peening time to record minimum value at 15 minutes then begins to increase to record the highest plastic deformation comparing with the as received at $10^{4} \& 10^{5}$ cycles. This indicate that there is a very limited increment in plastic deformation comparing with as received to record an increment in fatigue life that reach 13MPa for 104 and $22 \mathrm{MPa}$ for 105 at 15 minutes.

SEM morphology is taken near the true strain at $\sigma_{\mathrm{u}}$ for three specimens (un-peening, 15 and 30 minutes shot peening). Figure 11 shows the surface fracture of un-peening specimen. The fine size of dimples and microvoids coalescence at fracture surface can be observed. It is evidence that there is little number of secondary cracks.

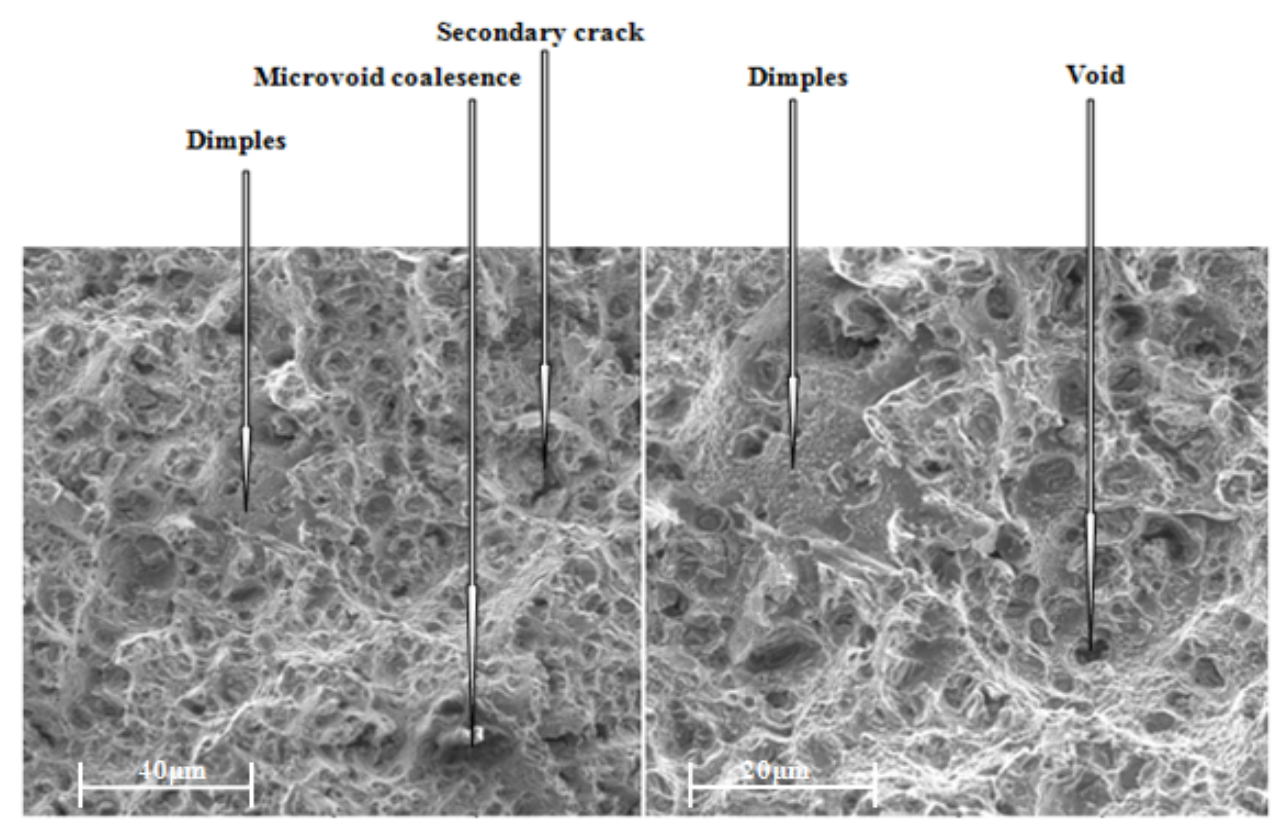

Figure 11. SEM of fracture feature of un-peened AA 2024-T4

Figure 12 shows the surface fracture microstructure of 15 minutes. shot peening, it can see the coarsens of dimples, also there is bigger microvoid coalescence and larger secondary cracks. The plastic deformation occurs from many individual shot impact craters, subsequently, void growth is driven by plastic deformation of the surrounding matrix. In the specific case of fracture in high strength Al-alloys, the intergranular damage is induced by growth of voids around coarsened precipitates in ductile Precipitate Free Zones. In cyclic loading, large single "craters" (due to particle embedding) appear close to or directly at the edge of the fracture surface. This is a strong indicator for failure originating from the surface (Khon et al., 2010). 


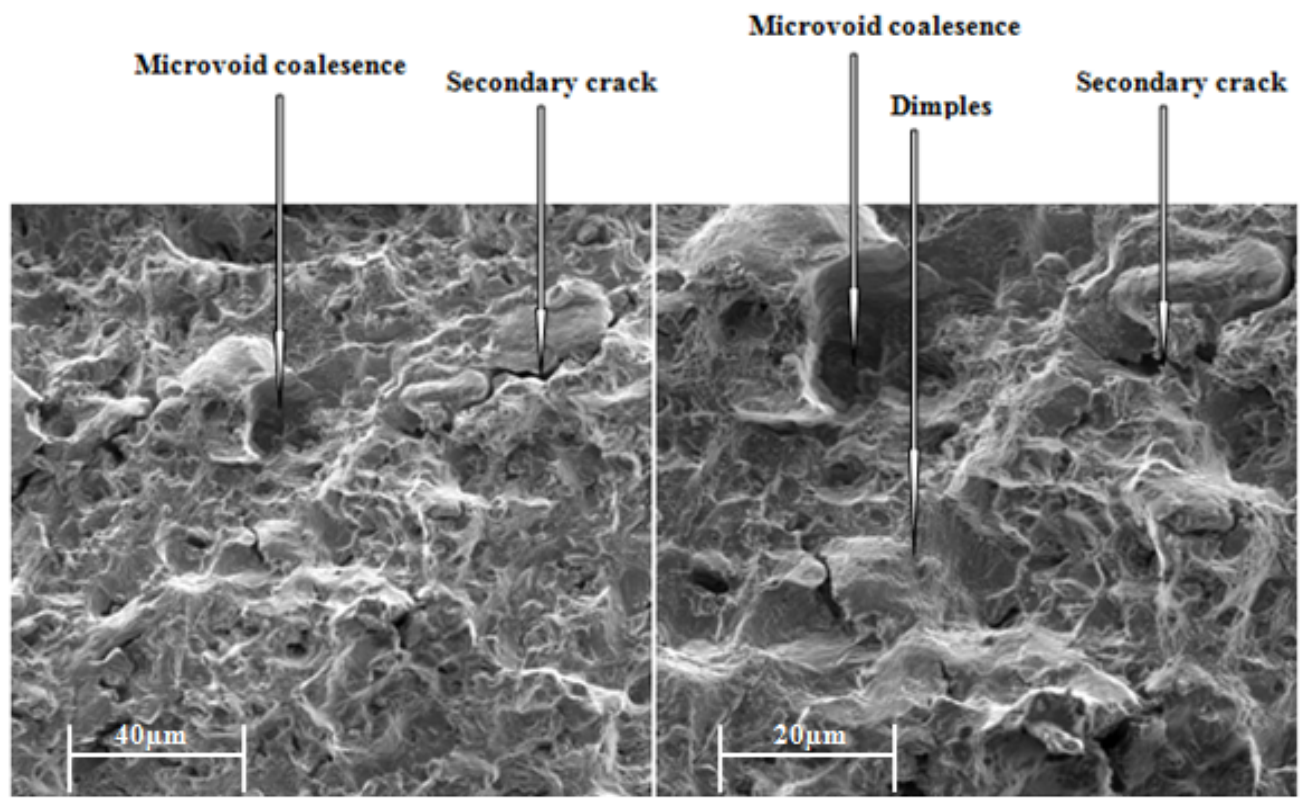

Figure 12. SEM of fracture feature of 15 minutes shot peening

Increasing shooting to $30 \mathrm{~min}$. (Figure 13) is associated with increasing the volume of voids, dimples size and secondary crack length, this explain the reduction in fatigue life for $30 \mathrm{~min}$ comparing with the as received state. It is evident that at high strain amplitude (near $\sigma_{u}$ ), the peening has a negative effect on low cycle behavior of AA 2024-T4 and this is related to the relaxation of induced residual compressive stresses, a single applied load that causes yielding in a region of residual stress (due to the superposition of residual and applied loads of the same sign) will result in changes in the residual stresses upon removal of the applied load. Repeated cyclic loading can also cause gradual changes in the residual stresses over time, even if no single fatigue cycle induces local yielding. So, the residual stresses can relax and redistribute due to cycling loading (Craig et al., 2005).

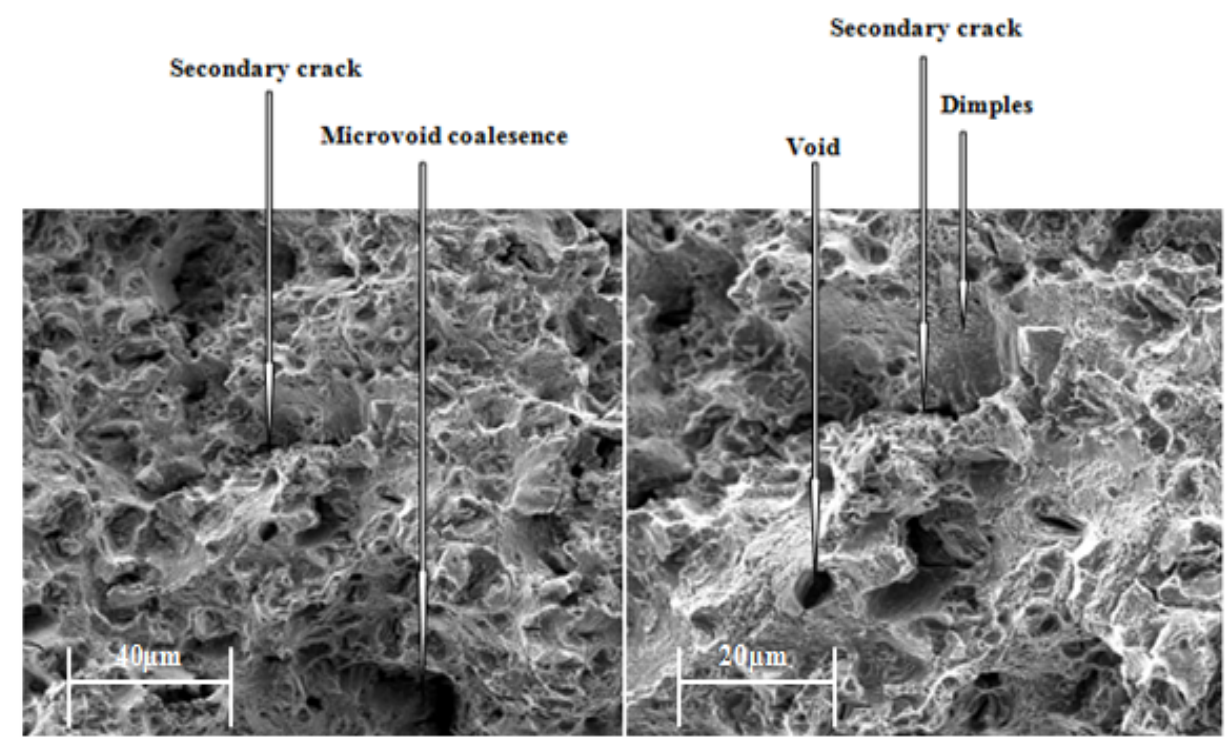

Figure 13. SEM of fracture feature of 30 minutes

\section{Conclusions}

1) Maximum benefit for monotonic tensile stress $\left(\sigma_{u} \& \sigma_{y}\right)$ for AA 2024-T4 is at 15 minutes peening time. 
2) Strain hardening exponent (n) slightly increases with increasing peening time and remain within the range of cycling hardening.

3) The improvement at strain life is clear after approximately 9000 cycles for 15 minutes peening time.

4) Low cycle fatigue near $\sigma_{u}$ for peening samples associated with increasing secondary crack length and microvoid coalescence.

5) $\mathrm{N}_{\mathrm{T}}$ is reducing with increasing shot peening time with increase in the corresponding strain till 15 minutes peening time.

6) The values of fatigue strength exponent (b) and fatigue ductility exponent (c) factors are within the metallic material range with increasing shot peening time up to $30 \mathrm{~min}$.

\section{References}

Anand, L., \& Parks, D. M. (2004). Defect Free Fatigue. Massachusetts Institute of Technology Department of Mechanical Engineering Cambridge, Mechanics and Materials II, spring, 1-37.

Asquith, D. T., Yerokhin, A. L., Yates, J. R., \& Matthews, A. (2006). Effect of Combined Shot-Peening and PEO Treatment on Fatigue Life of 2024 Al-Alloy. Thin Solid Films, 515, 1187-1191. http://dx.doi.org/10.1016/j.tsf.2006.07.123

Aghaie-Khafri, M., \& Zargaran, A. (2010). Low Cycle Fatigue Behaviour of AA 2618- T61 Forged Disk. Materials and Design. 31, 4104-4109. http://dx.doi.org/10.1016/j.matdes.2010.04.043

Afazov, S. M., Becker, A. A., \& Hyde, T. H. (2010). Effects of Micro-Stresses From Machining and Shot-Peening Processes on Fatigue Life. Int. J. Adv. Manuf. Technol., 51, 711-722. http://dx.doi.org/10.1007/s00170-010-2638-y

Benedetti, M., Bortolamedi, T., Fontanari, V., \& Frendo, F. (2003). Bending Fatigue Behaviour of Differently Shot Peened $\mathrm{Al} 6082$ T5 Alloy. International Journal of Fatigue, 26, 889-897. http://dx.doi.org/10.1016/j.jffatigue.2003.12.003

Borrego, L. P., Abreu, L. M., Costa, J. M., \& Ferreira, J. M. (2003). Analysis of Low Cycle Fatigue in AlMgSi Aluminum Alloys. Engineering Failure Analysis, 11, 715-725. http://dx.doi.org/10.1016/j.engfailanal.2003.09.003

Bhuvaraghan, B., Srinivasan, S. M., \& Maffeo, B. (2010). Optimization of the Fatigue Strength of Materials due to Shot Peening: A Survey. International Journal of Structural Changes in Solids, Mechanics and Applications, 2, 33-63.

Curtis, S., de los Rios, E. R., Rodopoulos, C. A., \& Levers, A. (2003). Analysis of the Effects of Controlled Shot Peening on Fatigue Damage of High Strength Aluminium Alloys. International Journal of Fatigue, 25, 59-66. http://dx.doi.org/10.1016/S0142-1123(02)00049-X

Craig McClung, R. (2005). A Bibliography and Abstracts on the Stability of Residual Stresses and There Influence on Fatigue. Southwest research institute, 1-102.

Everett, R. A., Matthews, W. T., Prabhakaran, R., Newman, J. C., \& Dubberly, M. J. (1993). The Effects of Shot and Laser Peening on Crack Growth and Fatigue Life in 2024 Aluminium Alloy and 4340 Steel. Nasa Centre for Aero Space Information (CASI). National Technical Information Service (NTIS).

Farahani, A. V., Kodric, T., \& Ghahramani, A. (2005). A Method of Fatigue Life Prediction in Notched and un-Notched Components. Journal of Materials Processing Technology, 169, 94-102. http://dx.doi.org/10.1016/j.jmatprotec.2005.01.015

Guagliano, M., \& Vergani, L. (2004). An Approach for Prediction of Fatigue Strength of Shot Peened $\begin{array}{llll}\text { Components. } \quad \text { Engineering } & \text { Fracture }\end{array}$ http://dx.doi.org/10.1016/S0013-7944(03)00017-1

Montross, C. S., Wei, T., Ye, L., Clark, G., \& Mai, Y. W. (2002). Laser Shock Processing and its Effects on Microstructure and Properties of Metal Alloys: A review. International Journal of Fatigue, 24. 1021-1036.

Mehmood, A., \& Hammouda, M. M. I. (2007). Effect of Shot Peening on the Fatigue Life of 2024 Aluminium Alloy. Department of Mechanical Engineering, University of Engineering \& Technology Taxila-Pakistan. pp. 1-12. 
Rahman, M. M., Kadirgama, K., Noor, M. M., Rejab, M. R. M., \& Kesulai, S. A. (2009). Fatigue Life Prediction of Lower Suspension Arm Using Strain-Life Approach. European Journal of Scientific Research, 30(3), 437-450. Retrieved from http://www.eurojournals.com/ejsr.htm

Sharp, P. K., \& Clarck, G. (2001). The Effect of Peening on the Fatigue Life of 7050 Aluminium Alloy. DSTO Aeronautical and Maritime Research Laboratory. 1-57.

Soady, K. A., Mellor, B. G., Shackleton, J., Morris, A., \& Reed, P. A. S. (2011). The Effect of Shot Peening on Notched Low Cycle Fatigue. Materials Science Centre, University of Manchester, M1 7HS, UK. 1-27.

Xiang, Y., \& Liu, Y. (2010). Mechanism Modeling of Shot Peening Effect on Fatigue Life Prediction. Department of Civil Engineering, Clarkson University, Potsdam, NY, 13699, USA. 1-32.

Yu, Y. H., \& Yu Y. H. (1986). The Effect of Shot Peening on Strain- Controlled Fatigue Behaviour. Nanjing Motors Research Institute, P. R. of China, 411-418. 